\title{
Acceptability, Feasibility, and Quality of Telehealth for Adolescent Health Care Delivery During the COVID-19 Pandemic: Cross-sectional Study of Patient and Family Experiences
}

Sarah M Wood ${ }^{1,2}$, MSHP, MD; Julia Pickel ${ }^{1,3}$, BA; Alexis W Phillips ${ }^{1}$, MPH; Kari Baber ${ }^{1,4}$, PhD; John Chuo ${ }^{1}$, MSc, MD; Pegah Maleki ${ }^{1}$, MPH, MSW, LSW; Haley L Faust ${ }^{1}$, BA; Danielle Petsis ${ }^{1}$, MPH; Danielle E Apple ${ }^{1}$, BSc; Nadia Dowshen $^{1,2,5}$, MSHP, MD; Lisa A Schwartz ${ }^{1,2}, \mathrm{PhD}$

\footnotetext{
${ }^{1}$ Division of Adolescent Medicine, Children's Hospital of Philadelphia, Philadelphia, PA, United States

${ }^{2}$ Department of Pediatrics, Perelman School of Medicine, University of Pennsylvania, Philadelphia, PA, United States

${ }^{3}$ Wake Forest School of Medicine, Winston-Salem, NC, United States

${ }^{4}$ Department of Psychiatry, Perelman School of Medicine, University of Pennsylvania, Philadelphia, PA, United States

${ }^{5}$ Leonard Davis Institute of Health Economics, University of Pennsylvania, Philadelphia, PA, United States
}

Corresponding Author:

Sarah M Wood, MSHP, MD

Department of Pediatrics

Perelman School of Medicine

University of Pennsylvania

3401 Civic Center Blvd.

Philadelphia, PA, 19104

United States

Phone: 12155901000

Email: woodsa@chop.edu

\section{Abstract}

Background: Data regarding the acceptability, feasibility, and quality of telehealth among adolescents and young adults (AYA) and their parents and caregivers (caregivers) are lacking.

Objective: The aim of this study was to assess the noninferiority of telehealth versus in-person visits by comparing acceptability with respect to efficiency, effectiveness, equity, patient-centeredness, and confidentiality.

Methods: Cross-sectional web-based surveys were sent to caregivers and AYA following video visits within an Adolescent Medicine subspecialty clinic in May-July 2020. Proportions of AYA and caregivers who rated telehealth as noninferior were compared using chi-squared tests. Feasibility was assessed via items measuring technical difficulties. Deductive thematic analysis using the Institute of Medicine dimensions of health care quality was used to code open-ended question responses.

Results: Survey response rates were 20.5\% (55/268) for AYA and 21.8\% (123/563) for caregivers. The majority of the respondents were White cisgender females. Most AYA and caregivers rated telehealth as noninferior to in-person visits with respect to confidentiality, communication, medication management, and mental health care. A higher proportion of AYA compared to caregivers found telehealth inferior with respect to confidentiality $(11 / 51,22 \%$ vs $3 / 118,2.5 \%, P<.001)$. One-quarter (14/55) of the AYA patients and 31.7\% (39/123) of the caregivers reported technical difficulties. The dominant themes in the qualitative data included advantages of telehealth for efficiency and equity of health care delivery. However, respondents' concerns included reduced safety and effectiveness of care, particularly for patients with eating disorders, owing to lack of hands-on examinations, collection of vital signs, and laboratory testing.

Conclusions: Telehealth was highly acceptable among AYA and caregivers. Future optimization should include improving privacy, ameliorating technical difficulties, and standardizing at-home methods of obtaining patient data to assure patient safety.

(JMIR Pediatr Parent 2021;4(4):e32708) doi: $\underline{10.2196 / 32708}$ 


\section{KEYWORDS}

telehealth; telemedicine; adolescent; COVID-19; acceptability; feasibility; young adult; teenager; cross-sectional; patient experience; experience; efficiency; equity; survey

\section{Introduction}

With the rapid shift to video visits during the COVID-19 pandemic, adolescents, who are typically digital natives, have been key consumers of technology-delivered health care [1]. Prior to COVID-19, telehealth was seen as a potential tool to increase access to care and reduce health disparities for adolescents, but geographic restrictions and limited reimbursement led to low utilization [2]. Widespread adoption of telehealth was facilitated by emergency waivers issued by the Centers for Medicare and Medicaid Services, which allowed for geographic flexibility and expanded reimbursement, and the proliferation of Health Insurance Portability and Accountability Act compliant videoconferencing platforms [3,4]. Most commercial insurers quickly followed in relaxing telehealth restrictions to keep pace.

With the rapid transition to telehealth during the COVID-19 pandemic, data gathering of end-user acceptability of telehealth has lagged. The crisis conditions of the pandemic resulted in minimal opportunity for stakeholder input and design from adolescents and young adults (AYA) and their families. Even prior to the pandemic, there were limited data on the acceptability of telehealth for adolescents, and existing studies were mostly confined to mental and sexual health care [5-7], thus neglecting other areas of adolescent health care delivery, including gender-affirming care and management of eating disorders. Although recent systematic reviews demonstrate acceptability of telehealth for a variety of pediatric and adult conditions and modest effect sizes for effectiveness for telemedicine management of pediatric conditions, including asthma, attention deficit hyperactivity disorder, and depression, the acceptability of video-delivered care for a broad sample of adolescent health conditions remains unknown $[1,8]$.

Telehealth for adolescent care presents unique use case challenges. Adolescent Medicine service providers navigate additional confidentiality barriers, frequently need to integrate mental health care into visits, and often practice within interdisciplinary care teams, including psychologists, nutritionists, and social workers. Additional protections are needed to maintain confidentiality during adolescent enrollment within electronic health portals and telehealth applications while still allowing for parent and caregiver (caregiver) proxy access to essential health care information [9]. For example, caution is needed to assure that sensitive test results (such as pregnancy testing) are not released to parents through portals without adolescent consent and that confidential telehealth visits for sexual health services are not "visible" to parents. Early analyses have demonstrated successful adoption of telehealth, with high uptake rates for adolescent health care over periods of just days to weeks $[9,10]$. However, separate from adoption metrics, acceptability and feasibility assessments are essential to assure that telehealth is delivered with equivalent confidentiality protections to in-person care. The importance of confidential care has been amplified by the pandemic, given the rising rates of mental health conditions that necessitate additional privacy protections for both data collection and treatment delivery [11]. Early data from Adolescent Medicine providers demonstrate challenges to ensuring privacy and confidentiality, despite use of headphones, platform chat functions, and yes/no history-taking questions [12]. Providers have also noted that some patients from lower socioeconomic status households experienced greater difficulty securing private space owing to more crowded living arrangements, thereby presenting a potential challenge to equity [12].

Concerns surrounding widespread implementation of telehealth for adolescents remain, including threats to quality of care across the Institute of Medicine (IOM) dimensions of health care quality: safety, effectiveness, timeliness, efficiency, equity, and patient-centeredness $[13,14]$. Although telehealth has the potential to increase the reach of health care, early data show that it may paradoxically worsen health disparities owing to differential access to wireless internet, private spaces for visits, and mobile devices across race and socioeconomic status $[15,16]$. An additional area for concern is patient safety, as the lack of hands-on physical examinations and standardized collection of vital signs could lead to errors in diagnosis [17].

The perspectives of both patients and caregivers are critical for assessing the acceptability of telehealth for adolescents. The American Academy of Pediatrics Supporting Pediatric Research in Outcomes and Utilization of Telehealth (SPROUT) research network developed the SPROUT Telehealth Evaluation and Measurement (STEM) framework, a mechanism to evaluate perspectives on telehealth across stakeholders [18]. The Experience branch of the STEM framework emphasizes the need to understand patient and caregiver perspectives on multiple visit aspects, including overall satisfaction, communication quality, and impact on family routines [18]. We therefore sought to examine patient and caregiver attitudes toward telehealth in an Adolescent Medicine subspecialty clinic system. Our primary aim was to determine the acceptability, feasibility, and quality of telehealth for delivery of adolescent health care among patients and caregivers. A secondary aim sought to evaluate the agreement between patient and caregiver responses on acceptability measures.

\section{Methods}

We conducted a cross-sectional web-based survey to assess attitudes toward telehealth in AYA and parents and caregivers (caregivers).

\section{Settings and Participants}

Participants or their dependents received care within an Adolescent Medicine subspecialty clinic, within a large academic pediatric hospital network in the Philadelphia area. The clinic provides contraceptive and gynecologic services, gender-affirming care, HIV treatment and prevention, and management of eating disorders for AYA. The clinic transitioned 
from $100 \%$ in-person visits to majority synchronous video visits starting March 2020 owing to the COVID-19 pandemic [10]. The telehealth platform allowed for a multiple user interface, and visits were attended by multiple clinical team members, including registered dieticians, social workers, psychologists, and interpreters as needed. Patients aged $\geq 13$ years who completed a video visit from May-July 2020 were eligible for enrollment. Caregivers were eligible if their child $<18$ years of age completed a video visit during the study period or if they accompanied their child 18 years or older in a video visit (ie, the patient did not attend the visit independently). Patients and caregivers could participate independent of each other, and the data therefore do not represent patient/caregiver dyads. Potential participants were called before their telehealth visit by study staff, had contact information confirmed, and were informed about the survey. After visits were completed, links to research electronic data capture-based surveys were sent via text message or email to the participant and, separately, their caregiver, per inclusion criteria.

\section{Measures}

The 32-item (AYA) and 29-item (caregiver) web-based surveys assessed telehealth acceptability and feasibility. Survey items were adapted from previously validated scales, and items were selected using a modified Delphi procedure with experts from Adolescent Medicine, psychology, and informatics [19]. Telehealth acceptability was measured on a 5-point Likert scale comparing telehealth to in-person care with respect to provider-patient communication, convenience, privacy, and achieving goals of care. Feasibility was assessed via questions regarding technical difficulties with visits. Additional independent measures were included for AYA and caregivers, respectively. AYA surveys included items addressing ability to find a private space for the visit and whether there were opportunities to speak with their provider alone. Caregivers provided both their own and their child's demographic information and completed an additional question on their perceptions of how well their child's concerns were addressed at telehealth visits compared to in-person visits. In order to capture additional perspectives on telehealth that may not have been captured in our measures, both surveys contained 3 open-ended questions: (1) what are the disadvantages of telehealth compared to in-person visits? (2) what are the advantages of telehealth compared to in-person visits? and (3) please let us know any additional areas in which you felt telehealth was different from in-person visits.

\section{Quantitative Analysis}

Demographic characteristics of patients and caregivers were assessed via descriptive statistics, including means, medians, and standard deviations. For items comparing in-person to telehealth visits, we assessed noninferiority of telehealth to in-person care by dichotomizing responses into 2 categories: telehealth better or the same as in-person and telehealth worse than in-person. As our primary aim was to assess acceptability for both caregivers and adolescents and to identify areas for optimization to assure joint acceptability, we compared proportions of each population rating telehealth as noninferior to in-person care by using chi-squared and Fisher exact test. All

analyses were completed in Stata 15 (College Station, TX, StataCorp LP).

\section{Qualitative Analysis}

Three independent coders qualitatively analyzed responses to the open-ended questions in the survey regarding telehealth advantages and disadvantages. The primary (AWP) and secondary (PM, HLF) coders reviewed the open-text survey responses by using a semiquantitative spreadsheet approach, which captured the descriptions and frequencies of themes. The patient and, separately, caregiver-specific responses were independently double-coded using deductive thematic analysis to identify themes unique to the patient and caregiver experiences. The coding team developed an initial codebook of themes based on consensus with each coder and then they separately applied the codebook themes to the entirety of the open-text survey data. Any coding discrepancies were resolved by consensus. To ground findings within an existing health care quality framework, the primary coder categorized the final themes according to the IOM dimensions of health care quality: safety, effectiveness, timeliness, efficiency, equity, and patient-centeredness $[13,14]$. All procedures were reviewed and deemed by the Institutional Review Board to be exempt as quality improvement.

\section{Results}

\section{Quantitative Data}

In May-June 2020, 268 and 563 surveys were deployed to unique AYA patients and caregivers, respectively, with a response rate of $20.5 \%$ (55/268) for AYA and $21.8 \%$ (123/563) for caregivers. The majority of the patient and caregiver respondents were White cisgender females (Table 1). The race and sex distributions of patient survey respondents were representative of the patient population seen by the clinic during spring 2019. The most common visit reasons were eating disorders (18/55, 33\% patients, 52/123, 42.3\% caregivers) and gynecology/reproductive health $(18 / 55,33 \%$ patients, $44 / 123$, $35.8 \%$ caregivers).

The majority of the visits were conducted by physician providers (Table 2). Most AYA and caregivers used a smartphone with a Wi-Fi connection for their telehealth visit. With respect to confidentiality, nearly all AYA $(54 / 55,98 \%)$ were able to identify a private space for their visit (Table 2) and 36 out of 55 AYA $(65 \%)$ spoke to a provider alone during their telehealth visit (Table 2). Of the 19 AYA who did not speak to their provider alone, $3(16 \%)$ wanted to do so (Table 2).

With regards to acceptability (Table 3), the majority of AYA and caregivers rated telehealth as noninferior to in-person visits with respect to privacy, communication, managing medication questions, and discussing test results, mood, and mental health. A significantly higher proportion of AYA compared to caregivers felt telehealth was inferior to in-person care with respect to privacy $(11 / 51,22 \%$ vs $3 / 118,2.5 \%$, respectively, $P<.001)$. There were no other significant differences between AYA and caregivers in the acceptability ratings across domains.

With respect to feasibility, 39 out of $123(31.7 \%)$ caregivers and 14 out of 55 AYA (25\%) reported technical difficulties with 
telehealth, including difficulty accessing the patient portal. use, and 97 out of 123 caregivers (78.8\%) and 38 out of 55 AYA However, 104 out 123 caregivers $(84.5 \%)$ and 49 out of 55 (69\%) reported that video visits improved efficiency of care, AYA $(89 \%)$ reported that the technology system was easy to including time saved, compared to in-person visits (Table 2).

Table 1. Demographic characteristics of the survey respondents.

\begin{tabular}{|c|c|c|}
\hline Characteristic & Patient survey $(\mathrm{n}=55)$ & Caregiver survey $(\mathrm{n}=123)$ \\
\hline Age $^{\mathrm{a}}$ (years), median (IQR) & $18(17-20)$ & $48(44-51)$ \\
\hline \multicolumn{3}{|l|}{ Race $^{\mathbf{a}, \mathbf{b}}, \mathbf{n}(\%)$} \\
\hline White & $42(76.4)$ & $104(86.7)$ \\
\hline Black & $9(16.4)$ & $14(11.7)$ \\
\hline Asian & $4(7.3)$ & $1(0.8)$ \\
\hline Native American & $1(1.8)$ & $3(2.5)$ \\
\hline Other & $4(7.3)$ & $2(1.7)$ \\
\hline Latina $^{a}$ & $7(12.7)$ & $6(5)$ \\
\hline \multicolumn{3}{|l|}{$\operatorname{Sex}^{\mathrm{a}}, \mathbf{n}(\%)$} \\
\hline Male & $10(18.2)$ & $7(5.8)$ \\
\hline Female & $45(81.8)$ & $113(94.2)$ \\
\hline \multicolumn{3}{|l|}{ Gender identity $^{\mathbf{a}}, \mathbf{n}(\%)$} \\
\hline Cisgender male & $11(20)$ & $7(5.8)$ \\
\hline Cisgender female & $31(56.4)$ & $113(94.2)$ \\
\hline Transgender male & $7(12.7)$ & 0 \\
\hline Transgender female & $2(3.6)$ & 0 \\
\hline Gender queer/nonconforming/nonbinary & $4(7.3)$ & 0 \\
\hline \multicolumn{3}{|l|}{ Visit reason $^{\mathbf{b}}, \mathbf{n}(\%)$} \\
\hline Eating disorder & $18(32.7)$ & $52(42.3)$ \\
\hline Gynecology/contraception & $18(32.7)$ & $44(35.8)$ \\
\hline Gender-affirming care & $12(21.8)$ & $27(22)$ \\
\hline HIV treatment/prevention & $3(5.5)$ & 0 \\
\hline Mental health/substance abuse & $3(5.5)$ & $2(1.6)$ \\
\hline Other & $4(7.3)$ & $4(3.3)$ \\
\hline
\end{tabular}

${ }^{\mathrm{a}}$ Data not provided by 3 (2.4\%) caregiver survey respondents.

${ }^{\mathrm{b}}$ Checkbox question: participants could select more than one category if applicable; therefore, percentages add to $>100 \%$. 
Table 2. Telehealth visit characteristics.

\begin{tabular}{|c|c|c|}
\hline & Patients $(\mathrm{n}=55), \mathrm{n}(\%)$ & Caregivers $(\mathrm{n}=123), \mathrm{n}(\%)$ \\
\hline Previous Adolescent Medicine visit & $41(74.6)$ & $98(79.7)$ \\
\hline \multicolumn{3}{|l|}{ Visit location } \\
\hline Home & $54(98.2)$ & $123(100)$ \\
\hline Other & $1(1.8)$ & 0 \\
\hline Able to identify private space & $54(98.2)$ & $\mathrm{N} / \mathrm{A}^{\mathrm{a}}$ \\
\hline \multicolumn{3}{|l|}{ Providers present ${ }^{\mathbf{b}}$} \\
\hline Physician & $47(85.5)$ & $91(74)$ \\
\hline Nurse practitioner/Physician assistant & $6(10.9)$ & $25(20.3)$ \\
\hline Nurse & $4(7.3)$ & $3(2.4)$ \\
\hline Psychologist/licensed professional counsellors & $2(3.6)$ & $12(9.8)$ \\
\hline Social worker & $2(3.6)$ & $2(1.6)$ \\
\hline Physical/occupational therapist & $1(1.8)$ & $2(1.6)$ \\
\hline Dietician & $5(9.1)$ & $6(4.9)$ \\
\hline Other & $1(1.8)$ & $5(4.1)$ \\
\hline \multicolumn{3}{|l|}{ Connection type $^{b}$} \\
\hline Wi-Fi & $47(85.5)$ & $101(82.1)$ \\
\hline Data & $13(23.6)$ & $35(28.5)$ \\
\hline \multicolumn{3}{|l|}{ Device used } \\
\hline Tablet & $8(14.5)$ & $26(21.1)$ \\
\hline Smartphone & $40(72.7)$ & $74(60.2)$ \\
\hline Desktop computer & $7(12.7)$ & $6(4.9)$ \\
\hline Laptop computer & 0 & $17(13.8)$ \\
\hline \multicolumn{3}{|l|}{ Difficulty of video visit use } \\
\hline Difficult & $3(5.5)$ & $10(8.1)$ \\
\hline Neutral & $3(5.5)$ & $9(7.3)$ \\
\hline Easy & $49(89.1)$ & $104(84.6)$ \\
\hline \multicolumn{3}{|l|}{ Technical difficulties ${ }^{b}$} \\
\hline No issues & $41(74.5)$ & $84(68.3)$ \\
\hline Video never worked/stopped working & $1(1.8)$ & $15(12.2)$ \\
\hline Audio never worked/stopped working & $5(9.1)$ & $15(12.2)$ \\
\hline Poor audio/video quality & $6(11)$ & $14(11.4)$ \\
\hline Resorted to telephone call & $2(3.6)$ & $6(4.9)$ \\
\hline Difficulty signing up for or starting the telehealth application & $3(5.5)$ & $11(8.9)$ \\
\hline \multicolumn{3}{|l|}{ Would participate in a video visit again } \\
\hline Disagree & $8(14.5)$ & $15(12.2)$ \\
\hline Neither agree nor disagree & $10(18.2)$ & $8(6.5)$ \\
\hline Agree & $37(67.3)$ & $100(81.3)$ \\
\hline \multicolumn{3}{|c|}{ Frequency of talking to health care provider alone during in-person visits ${ }^{c}$} \\
\hline Never/almost never & $6(14.6)$ & N/A \\
\hline Occasionally/sometimes & $15(36.6)$ & N/A \\
\hline Almost every time/every time & $20(48.8)$ & N/A \\
\hline
\end{tabular}




\begin{tabular}{lll}
\hline & Patients $(\mathrm{n}=55), \mathrm{n}(\%)$ & Caregivers $(\mathrm{n}=123), \mathrm{n}(\%)$ \\
\hline $\begin{array}{l}\text { Talked to provider alone in telehealth visit } \\
\text { Wanted to talk to provider alone }{ }^{\mathbf{d}}\end{array}$ & $36(65.4)$ & $\mathrm{N} / \mathrm{A}$ \\
$\quad$ Disagree & $7(36.8)$ & $\mathrm{N} / \mathrm{A}$ \\
$\quad$ Neither agree nor disagree & $9(47.4)$ & $\mathrm{N} / \mathrm{A}$ \\
$\quad$ Agree & $3(15.8)$ & $\mathrm{N} / \mathrm{A}$ \\
Convenience compared to in-person visit & & \\
$\quad$ Telehealth took longer & $8(14.5)$ & $14(11.4)$ \\
$\quad$ No difference & $6(10.9)$ & $7(5.7)$ \\
$\quad$ Telehealth saved time & $38(69)$ & $97(78.9)$ \\
Never had an in-person visit & $3(5.5)$ & $5(4.1)$ \\
\hline
\end{tabular}

${ }^{\mathrm{a}} \mathrm{N} / \mathrm{A}$ : not applicable.

${ }^{b}$ Participants could select more than one category if applicable; therefore, percentages add to $>100 \%$.

${ }^{c}$ Answered only by patients who had attended a previous adolescent clinic visit $(n=41)$.

${ }^{d}$ Answered only by patients who did not speak to their provider alone during their clinic visit $(n=19)$. 
Table 3. Comparison of patient and caregiver acceptability of telehealth. ${ }^{\mathrm{a}}$

\begin{tabular}{|c|c|c|c|}
\hline \multirow[t]{2}{*}{ Acceptability of telehealth, domain } & \multicolumn{2}{|c|}{ Telehealth visit noninferior to in-person visit, $\mathrm{n}(\%)$} & \multirow[t]{2}{*}{$P$ value } \\
\hline & Patients $(n=55)$ & Caregivers $(\mathrm{n}=123)$ & \\
\hline \multicolumn{4}{|l|}{ Safety } \\
\hline I felt comfortable with the privacy of the video visit. ${ }^{b}$ & $40(78.4)$ & $114(96.6)$ & $<.001$ \\
\hline \multicolumn{4}{|l|}{ Effectiveness } \\
\hline Obtaining prescription refills $\mathrm{s}^{\mathrm{c}}$ & $43(95.6)$ & $82(98.8)$ & .28 \\
\hline Managing medication side-effects and questions ${ }^{\mathrm{d}}$ & $43(93.5)$ & $87(97.8)$ & .22 \\
\hline Discussing test results $\mathrm{e}^{\mathrm{e}}$ & $42(97.7)$ & $72(96)$ & .54 \\
\hline Discussing mental health ${ }^{\mathrm{f}}$ & $39(78)$ & $99(89.2)$ & .05 \\
\hline Receiving referrals to other providers $\mathrm{g}$ & $41(97.6)$ & $74(98.7)$ & .59 \\
\hline \multicolumn{4}{|l|}{ Timeliness/efficiency } \\
\hline The visit was convenient for $\mathrm{me}^{\mathrm{h}}$ & $49(96.1)$ & $117(99.2)$ & .22 \\
\hline \multicolumn{4}{|l|}{ Equity } \\
\hline I felt comfortable with the way my provider communicated with me $\mathrm{i}^{\mathrm{i}}$ & $50(98)$ & $113(96.6)$ & .52 \\
\hline \multicolumn{4}{|l|}{ Patient-centeredness } \\
\hline I felt comfortable discussing private topics alone with my health care provider ${ }^{\mathrm{j}}$ & $45(86.5)$ & $109(94)$ & .11 \\
\hline I felt comfortable communicating with my health care provider ${ }^{b}$ & $48(94.1)$ & $112(94.9)$ & .55 \\
\hline I felt my provider paid attention to me $\mathrm{e}^{\mathrm{b}}$ & $49(96.1)$ & $118(100)$ & .09 \\
\hline I felt my provider listened to $\mathrm{me}^{\mathrm{b}}$ & $50(98)$ & $116(98.3)$ & .66 \\
\hline I felt my concerns were addressed ${ }^{b}$ & $50(98)$ & $115(97.5)$ & .65 \\
\hline
\end{tabular}

\footnotetext{
${ }^{\mathrm{a}}$ Chi-squared test was used.

${ }^{b}$ Not applicable or no prior in-person visit for 4 (7.3\%) patients and 3 (2.4\%) caregivers; data missing for 2 (1.6\%) caregivers.

${ }^{\mathrm{c}}$ Not applicable or no prior in-person visit for $10(18.2 \%)$ patients and $37(30.1 \%)$ caregivers; data missing for $3(2.4 \%)$ caregivers.

${ }^{\mathrm{d}}$ Not applicable or no prior in-person visit for $9(16.4 \%)$ patients and $29(24.6 \%)$ caregivers; data missing for 5 (4.1\%) caregivers.

${ }^{\mathrm{e}}$ Not applicable or no prior in-person visit for $12(21.8 \%)$ patients and 44 (35.8\%) caregivers; data missing for 4 (3.3\%) caregivers.

${ }^{\mathrm{f}}$ Not applicable or no prior in person visit for $5(9.1 \%)$ patients and $9(7.3 \%)$ caregivers; data missing for $3(2.4 \%)$ caregivers.

${ }^{\mathrm{g}}$ Not applicable or no prior in-person visit for 13 (23.6\%) patients and 45 (36.7\%) caregivers; data missing for 3 (2.4\%) caregivers.

${ }^{\mathrm{h}}$ Not applicable or no prior in-person visit for $3(5.5 \%)$ patients and $3(2.4 \%)$ caregivers; data missing for $1(1.8 \%)$ patient and $2(1.6 \%)$ caregivers.

${ }^{\mathrm{i}}$ Not applicable or no prior in-person visit for 4 (7.3\%) patients and $3(2.4 \%)$ caregivers; data missing for $3(2.4 \%)$ caregivers.

${ }^{\mathrm{j}}$ Not applicable or no prior in-person visit for $3(5.5 \%)$ patients and $5(4.1 \%)$ caregivers; data missing for $2(1.6 \%)$ caregivers.
}

\section{Qualitative Data}

Nearly half $(\mathrm{n}=26)$ of the 55 patients $(47 \%)$ and 86 of the 123 caregivers $(69.9 \%)$ completed the open-ended questions. The demographics of the patient and caregiver responses to the open-ended questions were reflective of the total survey population. The sample was largely White (19/26, 73\% AYA; $75 / 86,87 \%$ of caregivers) cisgender females (19/26, 73\% AYA; $75 / 86,87 \%$ of caregivers). Emergent themes within the IOM quality framework and exemplar quotes are shown in Table 4.

The most frequently cited advantage of telehealth compared to in-person visits was within the IOM dimension of Timeliness.
Both patients and caregivers indicated that time was saved from no commute or in-person waiting room time and reported financial savings from less work missed and no transportation costs. The second most common theme was "Improved access to care for vulnerable populations" within the Equity IOM domain. Patients and caregivers described telehealth as expanding access to people who may experience a variety of challenges with attending in-person Adolescent Medicine visits. Patients also discussed how telehealth improved equity in care delivery, including, but not limited to, reducing misgendering patients by clinic staff. 
Table 4. Advantages/disadvantages reported in the patient and caregiver open-ended survey responses.

\begin{tabular}{|c|c|c|c|}
\hline Construct, advantage/disadvantage & Themes & Frequency $^{\mathrm{a}}$ & Exemplar quotes \\
\hline \multicolumn{4}{|c|}{ Safety: Delivering health care that minimizes risks and harm, including avoiding preventable injuries and reducing medical errors } \\
\hline Advantage & Improved patient safety & 8 & $\begin{array}{l}\text {..There's a greater risk of getting COVID- } 19 \text { when you } \\
\text { do in-person visits rather than telehealth visits. [Patient] }\end{array}$ \\
\hline Disadvantage & $\begin{array}{l}\text { Increased safety risks due to lack of } \\
\text { hands-on data }\end{array}$ & 4 & $\begin{array}{l}\text {..I feel that there is potential for parents to miss or } \\
\text { overlook clues about teen eating disorders using } \\
\text { telemedicine as a primary treatment option. [Caregiver] }\end{array}$ \\
\hline Disadvantage & Decreased visit privacy & 10 & $\begin{array}{l}\text {..Due to my answer-giving at home, I feel it's not as } \\
\text { safe because I have neighbors... and our house is con- } \\
\text { nected to someone else's house. [Patient] }\end{array}$ \\
\hline
\end{tabular}

Effectiveness: Providing services based on scientific knowledge and evidence-based guidelines

\begin{tabular}{|c|c|c|c|}
\hline Advantage & $\begin{array}{l}\text { Improving adherence to treatment rec- } \\
\text { ommendations }\end{array}$ & 4 & $\begin{array}{l}\text {...Accountability for seeing the doctor has been a pe } \\
\text { erful motivator for our family to do the right thing. } \\
\text { [Caregiver] }\end{array}$ \\
\hline Disadvantage & Limited scope of practice & 47 & $\begin{array}{l}\text {...Telehealth is not able to easily address physical } \\
\text { problems, can't take blood pressure etc. [Patient] }\end{array}$ \\
\hline
\end{tabular}

Timeliness: Reducing delays in providing and receiving health care

\begin{tabular}{|c|c|c|c|}
\hline Advantage & $\begin{array}{l}\text { Allowed continuity of care during the } \\
\text { pandemic }\end{array}$ & 12 & $\begin{array}{l}\text {..I would not prefer [telehealth] as a matter of course } \\
\text { but appreciated this visit since there was no other alter- } \\
\text { native at the moment. [Caregiver] }\end{array}$ \\
\hline Advantage & Reduced delays in care & 16 & $\begin{array}{l}\text {...I know my child will be seen sooner vs coming in after } \\
\text { waiting months for appointments due to heavy schedules. } \\
\text { [Caregiver] }\end{array}$ \\
\hline Disadvantage & Disrupted care due to technical issues & 14 & $\begin{array}{l}\text {...After checking in, and downloading applications, } \\
\text { application repeatedly restarted, only worked for audio } \\
\text {.. cut out } 3 \text { different times and required Doctor/us to } \\
\text { switch to a phone call [Caregiver] }\end{array}$ \\
\hline Disadvantage & Visit workflow challenges & 2 & $\begin{array}{l}\text {..I was not made aware that the staff would call my } \\
\text { home phone...I specifically asked them not to call, and } \\
\text { the call disturbed... my family who were busy with online } \\
\text { job interviews and standardized tests. [Patient] }\end{array}$ \\
\hline
\end{tabular}

Efficiency: Delivering health care in a manner that maximizes resource use and avoids waste
Advantage
Improved convenience for families
102
...Usually an appointment ...takes us 4 hours and this
Advantage
Decreased cost to families
9
Disadvantage
Increased financial burden on families 1 only took 1 hour for the actual appointment. [Caregiver]
...So much cheaper than paying gas tolls and parking plus saves two hours of drive time. [Caregiver]
...My daughter does n't get weighed in or her vitals taken. We have to go to her primary for weight check and [orthostatic vital signs] ... which means I pay for a second doc visit. [Caregiver]

\section{Equity: Delivering health care that does not differ in quality according to personal characteristics}
Advantage
Improved quality of care for vulnerable 45 populations
...The front desk staff cant misgender me because I don't interact with them. [Patient]
Advantage
Increased access to care vulnerable 7 populations
Disadvantage impede care
...For people who are sick or nonmobile. these visits benefits [them] because they could still get the treatment they need right from home... [Patient]
Limited resources or technology access 2
...[Telehealth] may be hard for some people to use or have access to. [Patient]

Patient-centeredness: Providing care that takes into account the preferences and aspirations of individual service users
Advantage
Improved person-centered communica- 16 tion
...I loved it! Doctor was engaged and it felt like a regu- lar visit ... I felt like it was less intimidating. [Patient]
Advantage comfortable with telehealth appointments. [Caregiver] 


\begin{tabular}{|c|c|c|c|}
\hline Construct, advantage/disadvantage & Themes & Frequency $^{\mathrm{a}}$ & Exemplar quotes \\
\hline Disadvantage & $\begin{array}{l}\text { Environmental distractions may impede } \\
\text { care }\end{array}$ & 6 & $\begin{array}{l}\text {...My family is extremely nosey and it was hard to find } \\
\text { a quiet/safe place in my house. [Patient] }\end{array}$ \\
\hline Disadvantage & $\begin{array}{l}\text { Diminished clinician-patient communi- } \\
\text { cation and rapport }\end{array}$ & 28 & $\begin{array}{l}\text {...My daughter [was] able to leave the room if not } \\
\text { wanting to engage, where in person visits are more en- } \\
\text { gaging. [Caregiver] }\end{array}$ \\
\hline
\end{tabular}

${ }^{\mathrm{a}}$ Frequency of the coded theme among adolescents and young adults and caregivers.

With respect to the disadvantages of telehealth, the most common theme was "Limitations in scope of practice" within the Effectiveness IOM domain. Patients and caregivers discussed that the lack of hands-on physical examination and laboratory testing, which were felt to be essential for the delivery of evidence-based care, could lead to decreased quality of care. Patients and caregivers also frequently endorsed challenges to patient-centeredness, particularly in communication and building rapport. With respect to Equity, one caregiver described the financial burden of telehealth owing to the challenges with a limited scope of practice, where caregivers may be required to pay for separately for both a telehealth visit and an in-person laboratory visit to meet the health needs of their child.

Caregiver responses differed qualitatively from patient open-ended responses in 2 ways. First, caregivers placed greater emphasis on the importance of preexisting provider-patient relationships in successfully creating a comfortable visit environment via telehealth. Second, caregivers more commonly framed telehealth as advantageous with respect to patient-centeredness, including comfort, provider-patient communication, and engagement in visits.

\section{Discussion}

\section{Principal Findings}

Within an Adolescent Medicine clinic, we found high acceptability of telehealth among both patients and caregivers. The majority of the patients and caregivers reported that telehealth visits were easy to use and saved time and they expressed willingness to participate in another telehealth visit. Key areas for optimization in telehealth implementation included improving technical problems, which may limit uptake, and ensuring adequate confidentiality standards for AYA in the video visit setting. Although $>85 \%$ of respondents found the telehealth system easy to use, a quarter of the patients and nearly a third of caregivers reported experiencing at least one technical issue during their telehealth visit. The most common issue across both groups was malfunctioning of the audio component in the video visit. The analysis of telehealth satisfaction among pediatric neurology service providers during the COVID-19 pandemic similarly revealed high levels of satisfaction, despite nearly $40 \%$ encountering technical challenges, and the providers surveyed also reported that audio problems were the most common [16]. In order to optimize telehealth quality, it will be essential to resolve technical issues impacting communication of clinical information and treatment recommendations. As technology continues to rapidly evolve, health systems likely need to "go back to the drawing board" to conduct more extensive usability testing on their systems. The user-centered design process is typically part of scale-up of new mobile health interventions but was bypassed owing to the urgency of the pandemic. Periods of respite between COVID surges may provide an opportunity to refine the user experience. Lastly, as health systems optimize their technology, consideration should be given to integrating remote patient monitoring options such as heart rate monitors, actigraphy, and pulse oximetry to augment video history and examination findings [20-22]. These digital tools also hold promise as health-promoting interventions in their own right. Remote patient monitoring strategies with real-time patient feedback may improve disease self-management and treatment adherence in conditions such as asthma and diabetes for adolescents.

Privacy was the only acceptability measure in which we found divergence between caregivers and adolescents. A significantly higher proportion of patients rated telehealth as inferior to in-person care for privacy. This finding suggests that AYA perceptions of visit privacy may be more complex than the simple ability to identify a private space for the visit, which $>98 \%$ of patients were able to do. Prior research efforts with Adolescent Medicine providers have identified several strategies for optimizing privacy and confidentiality during telehealth visits. For at-home visits in which patients have access to adequate technology and space for the visit, these include the use of headphones, yes/no history-taking questions, use of chat functions, and using background white noise to lessen the chance that others in the household will overhear [12,23]. In efforts to improve telehealth privacy, special attention should be paid to adolescents who lack stable housing, private space, or consistent access to technology. These include creating dedicated patient telehealth "drop-in" kiosks stocked with computers or tablets and soundproof space at essential locations that may remain open in a public health crisis, such as pharmacies, primary care clinics, or schools. In addition, models from the Veterans Administration have demonstrated that delivery of tablets to unstably housed individuals is a feasible strategy for maintaining access to telehealth for vulnerable populations [12,15,23-25].

The high acceptability and convenience of telehealth reported by AYA patients and caregivers point to potential benefits of integrating telehealth visits in adolescent care in the future years. However, the future of telehealth in the United States remains uncertain. In April 2021 and July 2021, the US Department of Health and Human Services renewed the declaration of the COVID-19 pandemic as a public health emergency for an additional 90 days [26]. Under this renewal, the blanket waivers issued by the Centers for Medicare and Medicaid Services to increase geographic flexibility and expanded reimbursement remained in effect [3]. In the absence of a further renewal, however, many of these waivers may no longer apply, making 
telehealth far less feasible. Some commercial insurers began withdrawing additional provisions, allowing for expanded telehealth reimbursement in fall 2020, with more following in winter and spring 2021. Given broad state discretion, telehealth policy for Medicaid and Children's Health Insurance Policy is also in flux across states. High acceptability of telehealth suggests that the integration of telehealth as an additional care delivery mode may be highly beneficial. In addition, given the increasing rates of adolescent mental health diagnoses, suicidal ideation, and suicide attempts during the pandemic [27-29], telemedicine will be an essential means of delivering evidence-based mental health care to youth, given the dearth of available in-person services [1]. Whether our health system can rise to this challenge will depend on the continuation of policies that, by lessening geographic restrictions and achieving parity with in-person visit reimbursement rates, enabled widespread telehealth use.

Our analysis has several limitations. The survey response rate was low, and therefore, may not provide a complete picture of patient and caregiver experiences with telehealth. Surveys were sent to patients attending visits during May-June 2020, when COVID-19 cases were rapidly rising in the United States. Many patients and caregivers were experiencing abrupt changes to their routines and additional stressors during these months, which may have limited the response rate. However, the response rate of the patients compared to that of the caregivers was approximately the same, and the patient race and sex demographic distribution did not differ significantly from patients seen in the clinic for in-person visits during spring 2019. The majority of the respondents were White, non-Hispanic, cisgender females, and therefore, our results may not be generalizable to other populations. Previous analyses of telehealth during COVID-19 in both pediatric and adult populations have demonstrated racial and socioeconomic disparities in telehealth utilization, with non-White patients, Latinx patients, and patients with low median household incomes having both lower overall utilization and utilizing audio only visits more often than audio plus video [16,30-32]. These studies provide an early signal that rapid introduction of telehealth, in many instances, has led to the unintended consequence of widening the equity gap in health care delivery. Our telehealth platform was designed to allow multiple users, including interpreters, to attend visits. This multiuser interface may not be generalizable to less-resourced health systems, and thus, attention should be paid in future research to capture the experiences of populations with limited English proficiency in a diversity of health systems. Understanding and addressing emerging health disparities and evaluating telehealth acceptability among marginalized groups will be crucial in any future implementation of telehealth.

\section{Conclusions}

Widespread telehealth adoption in response to the COVID-19 pandemic altered health care delivery during 2020 and 2021. We demonstrate high acceptability of telehealth by AYA and caregivers of AYA, a population for which very little was previously known about the acceptability and feasibility of the use of telehealth. Our data support the importance of maintaining reimbursements for telehealth as a strategy for adolescent health care delivery. Future research addressing telehealth in adolescents should focus on ensuring equity, optimizing the end-user experience, and improving confidentiality protections.

\section{Acknowledgments}

This research was supported by career development funding from the National Institute of Mental Health grant K23MH119976 (SMW) and the Stoneleigh Foundation (ND). No funder was involved in design of the research or approval of the manuscript for publication.

\section{Authors' Contributions}

SMW, JC, KB, ND, and LAS conceived and designed this study. SMW was the primary writer of the manuscript, with DEA as the secondary writer. DP and JP conducted all quantitative statistical analyses. AWP, HLF, and PM conducted all qualitative analysis. All authors revised and reviewed the manuscript and approved the final copy.

\section{Conflicts of Interest}

None declared.

\section{References}

1. Badawy SM, Radovic A. Digital Approaches to Remote Pediatric Health Care Delivery During the COVID-19 Pandemic: Existing Evidence and a Call for Further Research. JMIR Pediatr Parent 2020 Jun 25;3(1):e20049 [FREE Full text] [doi: 10.2196/20049] [Medline: $\underline{32540841]}$

2. Olson CA, McSwain SD, Curfman AL, Chuo J. The Current Pediatric Telehealth Landscape. Pediatrics 2018 Mar;141(3):1-10 [FREE Full text] [doi: 10.1542/peds.2017-2334] [Medline: 29487164]

3. COVID-19 emergency declaration blanket waivers for health care providers. Centers for Medicare and Medicaid Services. URL: https://www.cms.gov/About-CMS/Agency-Information/Emergency/EPRO/Current-Emergencies/ Current-Emergencies-page [accessed 2021-11-02]

4. Notification of enforcement discretion for telehealth remote communications during the COVID-19 nationwide public health emergency. US Department of Health and Human Services. 2020. URL: https://www.hhs.gov/hipaa/for-professionals/ special-topics/emergency-preparedness/notification-enforcement-discretion-telehealth/index.html [accessed 2021-06-10] 
5. Williams RL, Meredith AH, Ott MA. Expanding adolescent access to hormonal contraception: an update on over-the-counter, pharmacist prescribing, and web-based telehealth approaches. Curr Opin Obstet Gynecol 2018 Dec;30(6):458-464. [doi: 10.1097/GCO.0000000000000497] [Medline: 30299318]

6. Sundstrom B, DeMaria AL, Ferrara M, Meier S, Billings D. "The Closer, the Better:" The Role of Telehealth in Increasing Contraceptive Access Among Women in Rural South Carolina. Matern Child Health J 2019 Sep;23(9):1196-1205. [doi: 10.1007/s10995-019-02750-3] [Medline: 31228142]

7. Roberts N, Hu T, Axas N, Repetti L. Child and Adolescent Emergency and Urgent Mental Health Delivery Through Telepsychiatry: 12-Month Prospective Study. Telemed J E Health 2017 Oct;23(10):842-846. [doi: 10.1089/tmj.2016.0269] [Medline: 28426367]

8. Shah AC, O'Dwyer LC, Badawy SM. Telemedicine in Malignant and Nonmalignant Hematology: Systematic Review of Pediatric and Adult Studies. JMIR Mhealth Uhealth 2021 Jul 08;9(7):e29619 [FREE Full text] [doi: 10.2196/29619] [Medline: $\underline{\text { 34255706] }}$

9. Patel PD, Cobb J, Wright D, Turer R, Jordan T, Humphrey A, et al. Rapid development of telehealth capabilities within pediatric patient portal infrastructure for COVID-19 care: barriers, solutions, results. J Am Med Inform Assoc 2020 Jul 01;27(7):1116-1120 [FREE Full text] [doi: 10.1093/jamia/ocaa065] [Medline: 32302395]

10. Wood SM, White K, Peebles R, Pickel J, Alausa M, Mehringer J, et al. Outcomes of a Rapid Adolescent Telehealth Scale-Up During the COVID-19 Pandemic. J Adolesc Health 2020 Aug;67(2):172-178 [FREE Full text] [doi:

10.1016/j.jadohealth.2020.05.025] [Medline: $\underline{\text { 32611509] }}$

11. Serlachius A, Badawy SM, Thabrew H. Psychosocial Challenges and Opportunities for Youth With Chronic Health Conditions During the COVID-19 Pandemic. JMIR Pediatr Parent 2020 Oct 12;3(2):e23057 [FREE Full text] [doi: 10.2196/23057] [Medline: 33001834]

12. Barney A, Buckelew S, Mesheriakova V, Raymond-Flesch M. The COVID-19 Pandemic and Rapid Implementation of Adolescent and Young Adult Telemedicine: Challenges and Opportunities for Innovation. J Adolesc Health 2020 Aug;67(2):164-171 [FREE Full text] [doi: 10.1016/j.jadohealth.2020.05.006] [Medline: $\underline{32410810]}$

13. Institute of Medicine. Crossing the quality chasm: a new health system for the 21 st century. In: Institute of Medicine (US) Committee on Quality of Health Care in America. USA: National Academies Press; 2001.

14. Institute OM. Current and future state of performance measurement and reporting. In: Performance Measurement: Accelerating Improvement. Washington DC, USA: National Academies press; 2005.

15. Evans YN, Golub S, Sequeira GM, Eisenstein E, North S. Using Telemedicine to Reach Adolescents During the COVID-19 Pandemic. J Adolesc Health 2020 Oct;67(4):469-471 [FREE Full text] [doi: 10.1016/j.jadohealth.2020.07.015] [Medline: 32768330]

16. Rametta SC, Fridinger SE, Gonzalez AK, Xian J, Galer PD, Kaufman M, et al. Analyzing 2,589 child neurology telehealth encounters necessitated by the COVID-19 pandemic. Neurology 2020 Sep 01;95(9):e1257-e1266 [FREE Full text] [doi: 10.1212/WNL.0000000000010010] [Medline: 32518152]

17. Daniel H, Sulmasy LS, HealthPublic Policy Committee of the American College of Physicians. Policy recommendations to guide the use of telemedicine in primary care settings: an American College of Physicians position paper. Ann Intern Med 2015 Nov 17;163(10):787-789 [FREE Full text] [doi: 10.7326/M15-0498] [Medline: 26344925]

18. Chuo J, Macy ML, Lorch SA. Strategies for Evaluating Telehealth. Pediatrics 2020 Nov;146(5):1-4 [FREE Full text] [doi: 10.1542/peds.2020-1781] [Medline: $\underline{32817398]}$

19. Parmanto B, Lewis AN, Graham KM, Bertolet MH. Development of the Telehealth Usability Questionnaire (TUQ). Int J Telerehabil 2016;8(1):3-10 [FREE Full text] [doi: 10.5195/ijt.2016.6196] [Medline: 27563386]

20. Roblyer D. Perspective on the increasing role of optical wearables and remote patient monitoring in the COVID-19 era and beyond. J Biomed Opt 2020 Oct;25(10):102703-1-102703-9 [FREE Full text] [doi: 10.1117/1.JBO.25.10.102703] [Medline: 33089674]

21. Sun S, Folarin AA, Ranjan Y, Rashid Z, Conde P, Stewart C, RADAR-CNS Consortium. Using Smartphones and Wearable Devices to Monitor Behavioral Changes During COVID-19. J Med Internet Res 2020 Sep 25;22(9):e19992 [FREE Full text] [doi: 10.2196/19992] [Medline: 32877352]

22. King D, Khan S, Polo J, Solomon J, Pekmezaris R, Hajizadeh N. Optimizing Telehealth Experience Design Through Usability Testing in Hispanic American and African American Patient Populations: Observational Study. JMIR Rehabil Assist Technol 2020 Aug 04;7(2):e16004 [FREE Full text] [doi: 10.2196/16004] [Medline: 32749229]

23. Carlson JL, Goldstein R. Using the Electronic Health Record to Conduct Adolescent Telehealth Visits in the Time of COVID-19. J Adolesc Health 2020 Aug;67(2):157-158 [FREE Full text] [doi: 10.1016/j.jadohealth.2020.05.022] [Medline: 32517972]

24. Garvin LA, Hu J, Slightam C, McInnes DK, Zulman DM. Use of Video Telehealth Tablets to Increase Access for Veterans Experiencing Homelessness. J Gen Intern Med 2021 Aug;36(8):2274-2282 [FREE Full text] [doi: 10.1007/s11606-021-06900-8] [Medline: 34027612]

25. Nachum S, Gogia K, Clark S, Hsu H, Sharma R, Greenwald PW. An Evaluation of Kiosks for Direct-to-Consumer Telemedicine Using the National Quality Forum Assessment Framework. Telemedicine and e-Health 2020 Jun 24:178-183. [doi: $\underline{10.1089 / \text { tmj.2019.0318] }}$ 
26. Renewal of the determination that a public health emergency exists nationwide as the result of the continued consequences of coronavirus disease 2019 (COVID-19) pandemic. Department of Health and Human Services. URL: https://www.phe.gov/ emergency/news/healthactions/phe/Pages/COVID-15April2021.aspx [accessed 2021-06-10]

27. Mayne SL, Hannan C, Davis M, Young JF, Kelly MK, Powell M, et al. COVID-19 and Adolescent Depression and Suicide Risk Screening Outcomes. Pediatrics 2021 Sep;148(3):1-11. [doi: 10.1542/peds.2021-051507] [Medline: 34140393]

28. Thorisdottir IE, Asgeirsdottir BB, Kristjansson AL, Valdimarsdottir HB, Jonsdottir Tolgyes EM, Sigfusson J, et al. Depressive symptoms, mental wellbeing, and substance use among adolescents before and during the COVID-19 pandemic in Iceland: a longitudinal, population-based study. Lancet Psychiatry 2021 Aug;8(8):663-672. [doi: 10.1016/S2215-0366(21)00156-5] [Medline: 34090582]

29. Yard E, Radhakrishnan L, Ballesteros MF, Sheppard M, Gates A, Stein Z, et al. Emergency Department Visits for Suspected Suicide Attempts Among Persons Aged 12-25 Years Before and During the COVID-19 Pandemic - United States, January 2019-May 2021. MMWR Morb Mortal Wkly Rep 2021 Jun 18;70(24):888-894 [FREE Full text] [doi: 10.15585/mmwr.mm7024e1] [Medline: 34138833]

30. Ye S, Kronish I, Fleck E, Fleischut P, Homma S, Masini D, et al. Telemedicine Expansion During the COVID-19 Pandemic and the Potential for Technology-Driven Disparities. J Gen Intern Med 2021 Jan;36(1):256-258 [FREE Full text] [doi: 10.1007/s11606-020-06322-y] [Medline: 33105000]

31. Kemp MT, Liesman DR, Brown CS, Williams AM, Biesterveld BE, Wakam GK, et al. Factors Associated with Increased Risk of Patient No-Show in Telehealth and Traditional Surgery Clinics. J Am Coll Surg 2020 Dec;231(6):695-702 [FREE Full text] [doi: 10.1016/j.jamcollsurg.2020.08.760] [Medline: 32891797]

32. Reed ME, Huang J, Graetz I, Lee C, Muelly E, Kennedy C, et al. Patient Characteristics Associated With Choosing a Telemedicine Visit vs Office Visit With the Same Primary Care Clinicians. JAMA Netw Open 2020 Jun 01;3(6):e205873 [FREE Full text] [doi: 10.1001/jamanetworkopen.2020.5873] [Medline: 32585018]

\section{Abbreviations}

AYA: adolescents and young adults

IOM: Institute of Medicine

SPROUT: Supporting Pediatric Research in Outcomes and Utilization of Telehealth

STEM: SPROUT Telehealth Evaluation and Measurement

Edited by S Badawy; submitted 23.08.21; peer-reviewed by S Pak-Gorstein, K Taylor; comments to author 13.09.21; revised version
received 27.09.21; accepted 06.10.21; published 15.11.21
Please cite as:
Wood SM, Pickel J, Phillips AW, Baber K, Chuo J, Maleki P, Faust HL, Petsis D, Apple DE, Dowshen N, Schwartz LA
Acceptability, Feasibility, and Quality of Telehealth for Adolescent Health Care Delivery During the COVID-19 Pandemic:
Cross-sectional Study of Patient and Family Experiences
JMIR Pediatr Parent 2021;4(4):e32708
URL: https://pediatrics.jmir.org/2021/4/e32708
doi: $10.2196 / 32708$
PMID:

(CSarah M Wood, Julia Pickel, Alexis W Phillips, Kari Baber, John Chuo, Pegah Maleki, Haley L Faust, Danielle Petsis, Danielle E Apple, Nadia Dowshen, Lisa A Schwartz. Originally published in JMIR Pediatrics and Parenting (https://pediatrics.jmir.org), 15.11.2021. This is an open-access article distributed under the terms of the Creative Commons Attribution License (https://creativecommons.org/licenses/by/4.0/), which permits unrestricted use, distribution, and reproduction in any medium, provided the original work, first published in JMIR Pediatrics and Parenting, is properly cited. The complete bibliographic information, a link to the original publication on https://pediatrics.jmir.org, as well as this copyright and license information must be included. 